\title{
Association of Human Leukocyte Antigen (HLA)-B5 and -BW22-J with Hepatic Cirrhosis of Apparently Unknown Etiology
}

\author{
Akiyuki Ohkubo, Kyoko Okimoto, Yasuhiko Iwasaki, \\ Kinori Kosaka, Takeo Juji* and Hiroshi Tohyama* \\ The Third Department of Internal Medicine, Faculty of Medicine, \\ University of Tokyo, and *Blood Transfusion Service, Tokyo \\ University Hospital, University of Tokyo, Tokyo 113
}

\begin{abstract}
Ohrubo, A, Okmoto, K, Iwasaki, Y, Kosaka, K, Juji, T. and Tohyama, H. Association of Human Leukocyte Antigen (HLA)-B5 and -BW22-J with Hepatic Cirrhosis of Apparently Unknoun Etiology. Tohoku J. exp. Med, 1977, 123 (3), 257-263 — The majority of patients with hepatic cirrhosis in Japan do not have a history of acute hepatitis or alcoholism. Twenty-nine patients with hepatic cirrhosis which were thought as random samples from cirrhotic patients without a history of acute hepatitis or alcoholism were Human Leukocyte Antigen (HLA) typed. Association of HLA-B5 and -BW22-J with hepatic cirrhosis of apparently unknown etiology was found in $p<0.003$, and $p<0.01$, respectively (128 controls). A predisposition linked to HLA-B5 or -BW22-J related gene or genes seems to play a role in the development of hepatic cirrhosis, at least in a substantial part of patients with hepatic cirrhosis of apparently unknown etiology in Japan. hepatic cirrhosis; HLA-B5; HLA-BW22-J
\end{abstract}

In Japan where alcoholism is not so prevalent as in Europe and the United States of America (Takata 1976), hepatic cirrhosis develops insidiously without a history of acute hepatitis or alcoholism in the majority of the patients (Matsushita 1975). In cases of chronic hepatitis following acute viral hepatitis, abnormal immune response has been assumed to play a role in the development of chronic hepatitis (Dudley et al. 1972; Eddleston and Williams 1974).

In 1972, Mackay and Morris reported association of certain specificities of the human major histocompatibility system, HLA-Al and -B8, with autoimmune active chronic hepatitis. Since then, several investigations on the association of certain specificities of HLA with chronic liver diseases have been reported on Caucasians (Freudenberg et al. 1973; Galbraith et al. 1974; Lindberg et al. 1975; Freudenberg et al. 1976).

These reports confirmed an association of HLA-B8 with chronic active hepatitis of apparently unknown etiology, but not with chronic active hepatitis with HBs antigenemia (Galbraith et al. 1974; Bertrams et al. 1974; Lindberg et al. 1975; Freudenberg et al. 1976). In contrast to chronic active hepatitis, a part of which

Received for publication, February 28, 1977. 
is expected to develop cirrhosis, few attempts have been reported to study association of certain specificities of HLA with hepatic cirrhosis. Mackay and Morris (1972) could not find association of certain HLA specificities with hepatic cirrhosis. Freudenberg et al. (1973) could not either find association of certain HLA specificities with hepatic cirrhosis as a whole. Bailey et al. (1976) reported a relatively high incidence of HLA-B8 in patients with alcoholic cirrhosis. However, after correction of $p$ value by the number of HLA antigens tested, the difference became insignificant.

This paper is to report association of HLA-BW22-J, a Japanese specific HLA antigen, and HLA-B5 with hepatic cirrhosis of apparently unknown etiology in Japan.

\section{Patients and Methods}

HLA types were determined for this first (A) and the second (B) loci with the lymphocytotoxicity technique (Terasaki and McClelland 1964). Some of the anti-HLA sera were favourably supplied from Drs. van Rood, Grumet, and Perkins. The remaining was prepared from multiparous women in our laboratory. In them, antisera by which two split antigens of $B W 22$ were identified were included. In 1973 we had identified Japanese specific split antigen of BW22 and reported it as J-l (Juji et al. 1973). This split antigen, which was named BW22-J by Japanese HLA Workshop Committee in 1977, had not been detected in 260 Caucasian lymphocyte samples (Juji et al. 1975). The other part of BW22 split antigens showed almost the same specificity as Caucasian BW22. All the HLA typed patients as well as the control 128 healthy subject were unrelated Japanese. Twenty-nine patients with hepatic cirrhosis who had visited our clinic in 1976 were HLA typed serially. The patients with hepatic cirrhosis accompanying congenital metabolic disorders, chronic circulatory failure, longstanding cholestasis, or alcoholism, and the patients with a history of acute hepatitis were excluded from HLA study. The diagnosis of hepatic cirrhosis was established histologically by needle biopsy. In 19 out of 29 cases, needle biopsy was carried out under laparoscopy. All the classifiable cases were those of posthepatitic cirrhosis according to the criteria of Gall (1960). Statistical analysis was done by the $\chi^{2}$ test with Yates' correction. The $p$ values given here were corrected for the number of antigens tested.

\section{REsUlts}

As shown in Table 1, any manifestations suggestive of acute hepatitis or alcoholism were not found in the early history of $70 \%$ of the patients with hepatic cirrhosis admitted to our department during 1972-1976.

Fig. 1 shows that the age incidence of the HLA typed with hepatic cirrhosis admitted to our department during 1972-1976. The distribution pattern of the age incidence of patients in this study was similar to that of 2421 cases of hepatic cirrhosis observed in a Japanese nation-wide epidemiological survey of chronic liver diseases in 1972 (Matsushita 1975). In that survey, congenital metabolic disorders, cardiac cirrhosis, and biliary cirrhosis were excluded. The male to female ratio of the HLA typed patients was 2.6 to 1 , and that of the inpatients was 2.5 to 1 . Thus, the HLA typed patients were considered as random samples out of the majority of the patients with hepatic cirrhosis of apparently unknown etiology in Japan. 
TABLE 1. Classification of the previous history of the patients with hepatic cirrhosis admitted to our department during 1972-19\%6

\begin{tabular}{ccc}
\hline Previous history & $\begin{array}{c}\text { Number of } \\
\text { patients }\end{array}$ & $\%$ \\
\hline $\begin{array}{c}\text { Acute hepatitis } \\
\text { Alcoholism } \\
\text { (alcohol intake } \\
\begin{array}{c}\text { l50 g/day) } \\
\text { None, attributable to } \\
\text { Total }\end{array}\end{array}$ & 6 & 6 \\
\hline
\end{tabular}

Hepatic cirrhosis with congenital metabolic disorders, cardiac cirrhosis, and biliary cirrhosis were excluded.
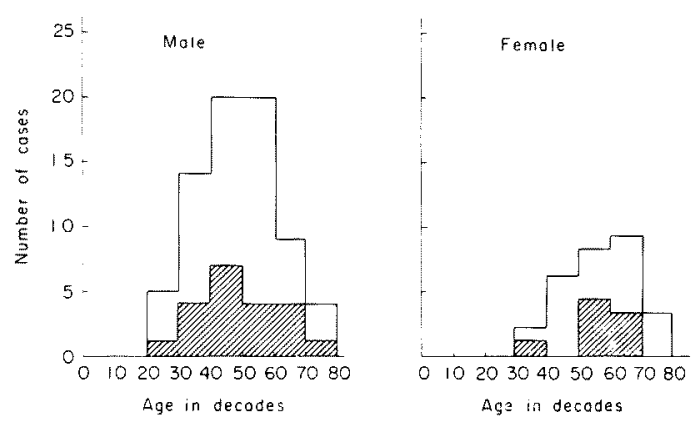

Fig. 1. The age and sex distribution of the patients with hepatic cirrhosis admitted to our department during 1972-1976. The shaded parts represent cases of the HLA type.

Table 2 shows the results of HLA typing of the patients with hepatic cirrhosis which had developed insidiously without a history of acute hepatitis or alcoholism. Out of 29 patients, 5 were positive for HBs antigen. Four patients (14\%) had cirrhotic patients in the family. In 2 out of these 4 cases of positive family history of liver diseases, HBs antigen was positive and was thought responsible for the familial occurrence of hepatic cirrhosis.

The incidence of hepatic cirrhosis in the family of the HLA typed patients was not different from the incidence of liver diseases in the family of the patients with hepatic cirrhosis reported in the nation-wide epidemiological survey $(11.3 \%)$ (Matsushita 1975). The incidence of hepatic cirrhosis among the family of the cirrhotic patients was thought high in comparison with the incidence of hepatic cirrhosis in general population in Japan. This high incidence of hepatic cirrhosis among the family may be explained by two factors, an environmental factor such as a viral infection within the family, and a genetic factor, i.e., susceptibility to hepatic cirrhosis. This study was done to clarify inheritable susceptibility to hepatic cirrhosis. In view of scanty evidence of homogeneous etiology in cases of the HLA typed hepatic cirrhosis, it was astonishing to find that 21 out of 29 patients with hepatic cirrhosis $(72 \%)$ were positive for HLA phenotype B5, and $11(38 \%)$ 
TABLE 2. Data of the patients with hepatic cirrhosis

\begin{tabular}{|c|c|c|c|c|c|c|c|c|c|}
\hline \multirow[b]{2}{*}{ No. } & \multirow[b]{2}{*}{ Name } & \multirow[b]{2}{*}{ Age } & \multirow{2}{*}{ Sex } & \multirow{2}{*}{$\begin{array}{c}\text { Abnormal } \\
\text { GTT }\end{array}$} & \multirow{2}{*}{$\begin{array}{c}\mathrm{HBs} \\
\text { antigen }\end{array}$} & \multirow{2}{*}{$\begin{array}{l}\text { Cirrhosis } \\
\text { in the } \\
\text { family }\end{array}$} & \multirow{2}{*}{$\begin{array}{l}\text { Diabetes } \\
\text { in the } \\
\text { family }\end{array}$} & \multicolumn{2}{|c|}{ HLA locus } \\
\hline & & & & & & & & A & B \\
\hline 1 & H.K. & 55 & $\mathrm{~F}$ & + & - & - & - & 2,9 & 5, WI6 \\
\hline 2 & M.I. & 43 & $\mathrm{M}$ & + & - & - & - & 2,9 & $5, W 22 . J$ \\
\hline 3 & T.On. & 47 & $\mathrm{M}$ & + & + & - & - & 9 & 5 \\
\hline 4 & T.ok. & 70 & $\mathrm{~F}$ & + & - & - & - & 9,11 & 5 \\
\hline 5 & Y.S. & 51 & M & + & - & - & - & 9, W19 & $5, W 35$ \\
\hline 6 & M.T. & 52 & $\mathrm{M}$ & + & - & - & - & 9 & $5, W 22 \cdots J$ \\
\hline 7 & M.M. & 40 & M & + & - & + & + & 9,11 & 5,8 \\
\hline 8 & F.W. & 42 & $\mathrm{M}$ & + & - & - & - & 2,9 & 5, W35 \\
\hline 9 & T.T. & 44 & M & + & - & - & - & 2,10 & W40, W22-J \\
\hline 10 & N.T. & 58 & $\mathrm{M}$ & + & + & - & - & 9,10 & W16, W40 \\
\hline 11 & H.Y. & 66 & $\mathrm{~F}$ & + & - & - & - & 9, W19 & $5, \mathrm{~W} 22 . \mathrm{J}$ \\
\hline 12 & K.Su. & 56 & $\mathrm{~F}$ & - & - & - & + & $2, W 19$ & W15, W22-J \\
\hline 13 & G.M. & 66 & M & - & - & - & - & 9 & $7, \mathrm{~W} 22-\mathrm{J}$ \\
\hline 14 & $\mathrm{~K} . \mathrm{N}$. & 41 & M & - & - & - & - & 2,9 & W15, W22-J \\
\hline 15 & T.S. & 39 & M & - & - & - & - & 10,11 & $5, W 22-\mathbf{J}$ \\
\hline 16 & F.T. & 63 & $\mathrm{M}$ & - & - & - & - & $9, W 19$ & $12, W 15$ \\
\hline 17 & T.Oo. & 73 & $\mathrm{M}$ & - & + & - & - & 9 & 5 \\
\hline 18 & T.K. & 55 & $\mathrm{~F}$ & - & - & - & - & 9 & 5 \\
\hline 19 & T.M. & 37 & M & - & - & - & - & 2,10 & $5 . W_{15}$ \\
\hline 20 & S.I. & 61 & $M$ & - & - & - & - & 9,10 & $5, W 40$ \\
\hline 21 & S.Oz. & 44 & $M$ & - & - & - & - & 2 & 5 \\
\hline 22 & S.Oo. & 45 & M & - & - & - & - & $10, W_{19}$ & $W_{15}, W_{40}$ \\
\hline 23 & N.S. & 59 & M & - & - & - & - & 9 & $5, \mathrm{~W} 22-\mathrm{J}$ \\
\hline 24 & K.K. & 27 & $\mathrm{M}$ & - & + & + & - & 9, W 19 & $5, W 16$ \\
\hline 25 & K.Se. & 36 & $\mathrm{~F}$ & - & - & - & - & 9,10 & 5. W40 \\
\hline 26 & A.S. & 63 & $\mathrm{~F}$ & - & - & - & - & 2 & $5, W 40$ \\
\hline 27 & K.o. & 40 & M & - & + & + & - & 9 & 5. W22-J \\
\hline 28 & I.T. & 52 & $\mathbf{F}$ & - & - & + & - & 9,11 & $5, \mathrm{~W} 22 \mathrm{~J}$ \\
\hline 29 & T.S. & 63 & M & - & - & - & - & 9 & W15, W35 \\
\hline
\end{tabular}

Glucose tolerance test (GTT) was diagnosed abnormal when the blood glucose at $60 \mathrm{~min}$ after oral administration of $100 \mathrm{~g}$ glucose was more than $180 \mathrm{mg} / 100 \mathrm{ml}$, the blood glucose at $120 \mathrm{~min}$ more than $160 \mathrm{mg} / 100 \mathrm{ml}$, and the ratio of the increase of whole blood insulin (IRI) in the first $30 \mathrm{~min}$ after glucose administration to the increase of blood glucose was less than 0.4 .

positive for HLA phenotype BW22-J. In the control group, 41 out of $128(32 \%)$ were positive for $\mathrm{B} 5$, and $13(10 \%)$ for BW22-J. The differences in the frequencies of B5 and BW22-J between the patients and the controls were statistically significant $(p<0.003$, and relative risk $=5.57$, for $\mathrm{B} 5: p<0.01$, and relative risk $=5.40$, for $\mathrm{BW}$ $22-J)$ as shown in Table 3.

\section{DIsCUSSION}

Occurrence of the HLA antigens in such a high frequency in the cases which were considered as random samples from the patients with hepatic cirrhosis of unknown etiology strongly suggests that a predisposition linked to HLA associated genes plays an important role in development of hepatic cirrhosis of otherwise unknown etiology in Japan. Knowledge about the way of intervention of HLA associated genes in the development of hepatic cirrhosis in these patients is not 
TABLE 3. Comparison between the patients with hepatic cirrhosis of unknown etiology and the healthy controls with regard to the frequency of $H L A$ phenotypes in the first $(A)$ and the second $(B)$ loci

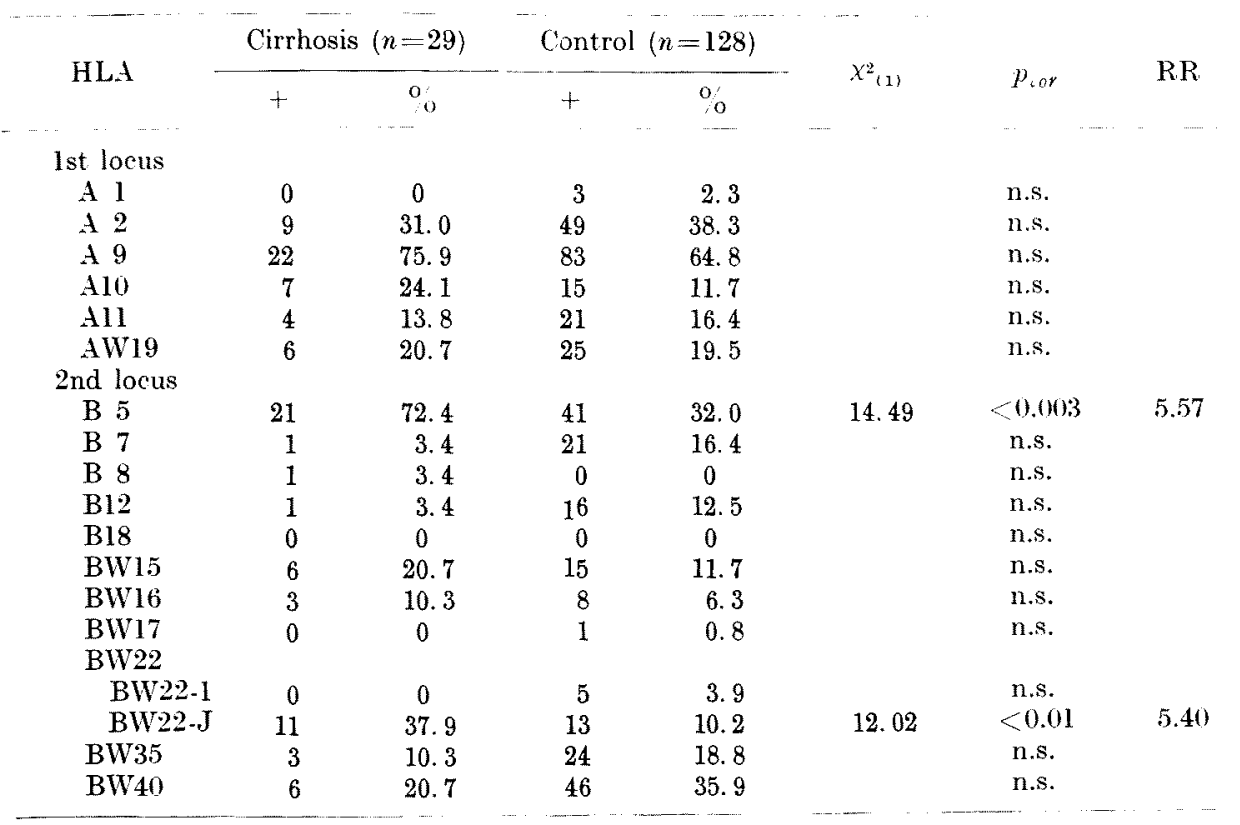

$p_{\text {cor }}, p$ value corrected for the number of antigens investigated (× 18); RR, relative risk.

only interesting but also indispensable for prevention and treatment of hepatic cirrhosis. As for BW22-J, Ohtawa et al. (1974) reported association of this HLA specificity with thromboangiitis obliterans. According to Okimoto et al. (1977), BW22-J associates also with the juvenile-onset type of diabetes, but not with the adult-onset type of diabetes in Japanese (unpublished work). In our series of hepatic cirrhosis, $38 \%$ of the cases were accompanied with abnormal oral glucose tolerance test (GTT). But, the difference in the frequency of BW22-J between the patients with abnormal GTT and the patients without it was not statistically significant: The frequency of BW22-J is rare among Caucasians as mentioned before (Juji et al. 1975). Instead of BW22-J, B8, the frequency of which is reported to be rare among. Japanese (Mittal et al. 1973; Yasuda et al. 1976) has been reported to associate with the juvenile-onset type of diabetes in Caucasians (Nerup et al. 1974; Thomsen et al. 1975). B8 has also been reported to associate with several autoimmune diseases such as myasthenia gravis (Pirskanen et al. 1972; Feltkamp et al. 1974), Graves' disease (Grumet et al. 1973) as well as autoimmune chronic hepatitis in Caucasians (Freudenberg et al. 1973; Galbraith et al. 1974; Lindberg et al. 1975; Freudenberg et al. 1976). But, from the age and sex distribution of the patients, it seems difficult to assume that most of these HLA typed patients suffered from autoimmune chronic hepatitis described by Mackay et al. (1965). LE cells were negative for all the cases investigated, and anti-thyroid antibody were 
negative for most of these cases.

Up to date, only one attempt to find association of certain specificities of HLA with chronic liver diseases was reported in Japan (Ito et al. 1975). In that paper, hepatic cirrhosis was not described, and 15 cases of chronic active hepatitis and 8 cases of autoimmune chronic hepatitis in accord with the criteria of Mackay et al. (1965) were reported not to associate with any specificities of HLA. These results suggest that ethnic difference between Japanese and Caucasians must be taken into account in study of susceptibility to liver diseases in relation to HLA antigens. The way of intervention of BW22-J associated genes in the development of hepatic cirrhosis in Japanese seems to be similar to, but probably not the same as, that of B8 associated genes in the development of hepatic cirrhosis in Caucasians. The problem remains to be clarified.

B5 is one of the commonest HLA specificities in Japanese, and also common in Caucasians. Association of polycystic kidney (Dausset and Hors 1975), Behçet's disease (Ohno et al. 1973), and Buerger's disease (McLoughlin et al. 1976) with B5 were reported. From the consideration of these reports and our findings, the predisposition linked to B5 associated genes seems to intervene with the development of hepatic cirrhosis in ways different from the predisposition linked to BW22$\mathbf{J}$ associated genes. In other words, the HLA typed patients in this study, and probably the majority of the patients with hepatic cirrhosis of apparently unknown etiology in Japan were thought to have a predisposition linked to HLA associated genes and devided into probably two different groups in terms of the way of intervention of HLA associated genes in the development of hepatic cirrhosis. Anyway, a substantial part of the patients with hepatic cirrhosis in Japan are expected to bear a predisposition linked to HLA associated genes.

\section{Acknowledgment} helps.

We are grateful to Drs. Yokoyama, S., Muto, Y., and Akanuma, Y. for various

\section{References}

1) Bailey, R.J., Krasner, N., Eddleston, A.L.W.F. . Williams, R., Tee, D.E.H., Doniach, D., Kennedy, L.A. \& Batchelor, J.R. (1976) Histocompatibility antigens, autoantibodies, and immunoglobulins in alcoholic liver disease. Brit. med. J., 2, 727-729.

2) Bertrams, J., Reis, H.E., Kuwert, E. \& Selmair, H. (1974) Hepatitis associated antigen (HAA), HL-A antigens and autolymphocytotoxins (CoCoCy) in chronic aggressive and chronic persistent hepatitis. $Z$. Immun. Forsch., 146, 300-307.

3) Dausset, J. \& Hors, J. (1975) Some contributions of the HL-A complex to the genetic of human diseases. Transplant. Rev., 22, 44-74.

4) Dudley, F.J., Fox, R.A. \& Sherlock, S. (1972) Cellular immunity and hepatitisassociated, Australia antigen liver disease. Lancet, 1, 723-726.

5) Eddleston, A.L.W.F. \& Williams, P. (1974) Inadequate antibody response to HB Ag or Suppressor T-cell defect in development of active chronic hepatitis. Lancet, 2, 15431545 .

6) Feltkamp, T.E.W., van den Berg-Loonen, P.M., Nijenhuis, L.E., Engelfriet, C.P. van Rossum, A.L., van Loghem, J.J. \& Oosterhuis, H.J.G.H. (1974) Myasthenia gravis, autoantibodies, and HL-A antigens. Brit. med. $J ., 1,131-133$. 
7) Freudenberg, J., Erdmann, K., Meyer zum Büschenfelde, K.H., Förster, E. \& Berger, J. (1973) HL.A bei Lebererkrankungen. Klin. Wschr., 51, 1075-1076.

8) Freudenberg, J., Meyer zum Büschenfelde, K.H., Arnold, W., Berger, J., Weiller, H., Knolle, J., Hopf, U. \& Hütteroth, T. (1976) Histokompatibilitäts-(HLA) Antigene bei Patienten mit $\mathrm{HBs}$-Ag-positiver und negativer chronisch activer Hepatitis und gesunden Trägern von HBs Ag und Anti-HBs. Klin. Wschr., 54, 579-583.

9) Galbraith, R.M., Eddleston, A.L.W.F., Smith, M.G.M., Williams, R., MeSween, R.N.M., Watkinson, G., Dick, H., Kennedy, L.A. \& Batchelor, J.R. (1974) Histocompatibility antigens in active chronic hepatitis and primary biliary cirrhosis. Brit. med. J., 3, $604-605$.

10) Gall, E.A. (1960) posthepatitic, postnecrotic and nutritional cirrhosis. Amer. J. Path., 36, 241-271.

11) Grumet, C., Konishi, J., Payne, R.O. \& Kriss, J.P. (1973) Association of Graves' disease with HL-A8. Clin. Res., 21, 493.

12) Ito, K., Nakagawa, J. \& Sano, M. (1975) Cell-mediated immunity and HL-A antigen in the patients with chronic liver diseases. Clin. Immun., 7, 1107-1113. (Japanese)

13) Juji, T., Hagino, Y., Tamura, M. \& Okochi, K. (1973) A possibly new Japanesespecific HL-A antigen (J-1). Jap. J. exp. Med., 43, 447-449.

14) Juji, T., Hagino, Y., Tamura, M., Ohtawa, T., Toyama, H., Shibata, Y., Schreuder, I. \& van Rood, J.J. (1975) Absorption study on crossreactivity between W22 and J-1 antigens. In: Histocompatibility Testing 1975, edited by F. Kissmeyer-Nielsen, Mungsgaard, Copenhagen, pp. 283-288.

15) Lindberg, J., Lindholm, A., Lundin, P. \& Iwarson, S. (1975) Trigger factors and HL-A antigens in chronic active hepatitis. Brit. med. J., 4, 77-79.

16) Mackay, I.R. \& Morris, P.J. (1972) Association of autoimmune active chronic hepatitis with HL-Al, 8. Lancet, 2, 793-795.

17) Mackay, I.R., Weiden, S. \& Hasker, J. (1965) Autoimmune hepatitis. Ann. N.Y. Acad. Sci., 124, 767-780.

18) Matsushita, H., (1975) Epidemiology of hepatic cirrhosis in Japan. In: Hepatic Cirrhosis, edited by T. Oda, Ist ed., Nankodo, Tokyo, pp. 15-26.

19) MeLoughlin, G.A., Helsby, C.R., Evans, C.C. \& Chapman, D.M. (1976) Association of HLA-A9 and HLA-B5 with Buerger's disease. Brit. med. J., 2, 1165-1166.

20) Mittal, K.K., Hasegawa, T., Ting, A., Mickey, M.R. \& Terasaki, P.I. (1973) Genetic variation in the HL.A system between Ainus, Japanese, and Caucasians. In: Histocompatibility Testing 1972, edited by J. Dausset \& J. Colombani, Munksgaard, Copenhagen, pp. 187-195.

21) Nerup, J., Platz, P., Andersen, O.O., Christy, M., Lyngsøe, J., Poulsen, J.E., Ryder, L.P., Nielsen, L.S., Thomsen, M. \& Svejgaard, A. (1974) HL-A antigens and diabetes mellitus. Lancet, 2, 864-866.

22) Ohno, S., Aoki, K., Sugiura, S., Nakayama, E., Itakura, K. \& Aizawa, M. (1973) HL-A5 and Behçet's disease. Lancet, 2, 1383-1384.

23) Ohtawa, T., Juji, T., Kawano, N., Mishima, Y., Tohyama, H. \& Ishikawa, K. (1974) HL-A antigens in thromboangiitis obliterans. $J$. Amer. med. Ass., 230, 1128.

24) Pirskanen, R., Tiilikainen, A. \& Hokkanen, E. (1972) Histocompatibility (HL-A) antigens associated with myasthenia gravis. Ann. clin. Res., 4, 304-306.

25) Takata, A. (1976) Alcoholic liver injury in Japan. Saishin-Igaku, 31, 2113-2118. (Japanese)

26) Terasaki, P.I. \& McClelland, J.D. (1964) Microdroplet assay of human serum cytotoxins. Nature, 204, 998-1000.

27) Thomsen, M., Platz, P., Andersen, O.O., Christy, M., Lygsøe, J., Nerup, J., Rasmussen, K., Ryder, L.P., Nielsen, L.S. \& Svejgaard, A. (1975) MLC typing in juvenile diabetes mellitus and idiopathic Addison's disease. Transplant. Rev., 22, 125-147.

28) Yasuda, N., Tsuji, K., Aizawa, M., Itakura, K., Inou, T., Matsukura, M., Yoshida, T., Fukunishi, T., Orita, K., Nomoto, K. \& Ito, M. (1976) HLA antigens in Japanese populations. Amer. J. Hum. Genet., 28, 390-399. 